\title{
Simulation Research on the training mode for sports talents based on system
}

\section{dynamics}

Pan Shi-yi

(Luzhou Vocational and Technical College, Department of Basic, Luzhou, Sichuan 646005)

\begin{abstract}
Introducing the demand trends and training modes of sports talents, the paper points out that the urgent need of colleges, trained in universities is far from the requirement, the misunderstanding in as training units of sports talents, is to establish proper sports training model. The paper presents a researching model for training mode of sports talents to solve the defect of lack of practical research. Data of enrollment and employment, professional courses setting and talents training status of sports students in Sichuan Province from 2002 to 2012 are selected as objects to be analyzed in the research. The results show that the model for training of social sports talents based on system dynamics can satisfactorily simulate the training process, and the results are validated by the effectiveness test. However, there are still lots of factors cause the low sensitiveness and stability of the simulation model, such as the amount of professional talents courses setting and the diversification of employment destination of graduates.
\end{abstract}

Keywords-system dynamics; Social sports talents ; training mode; Simulation

\section{INTRODUCTION}

Recently, with China's rapid economic development, the people's living standards and the quality have greatly improved, and health has become the matter people most concerned. More and more people consciously participate in leisure, entertainment-based fitness activities. With the continues increase of the number of people participating in sports and the vigorous development of the sports industry, a large number of sports professionals are needed, so training model of social sports professionals becomes a hotspot ${ }^{[1]}$.

Currently, the training of social sports professionals mainly comes from universities. Social Sports Specialty in China is still in its infancy, so its training mode is also in the phase of theoretical research ${ }^{[2]}$. This paper presents a simulation model for training mode of sports talents based on system dynamics, in order to remedy the defects in enrollment and employment of universities. In the model, data of enrollment and employment, professional courses setting and talents training status of sports students in Sichuan Province are selected as objects to be analyzed in the research to adjust the validity and sensitivity of the model.

\section{THE PRINCIPLE OF THE SIMULATION MODEL FOR PERSONNEL TRAINING}

Accompanying with growth of sports professionals demand, the structural differences emerged in Cultivation of Sports Talent and the employment process in our society need to be resolved. To find the causes of the structural differences by establishing training mode for sports talents based on system dynamics is the most important issue ${ }^{[3]}$.

\subsection{The principle of the simulation model for Sports Professionals training}

Based on the principle of system dynamics, simulation model for Sports training mode integrates the behavior and decision-making rules of enrollment personnel training, professional setting and employment of college sports professional into a network for personnel training mode, thereby establishes an open information feedback system. Using students flow cash flow, equipment flow, knowledge flow, material flow and information flow as basic flows, the simulation model finds the causes of the structure changes of professionals' knowledge and sports skill, and then finds the reason leads to structural differences between the training and employment needs of sports professionals. The basic structure of the model is shown in Figure 1 


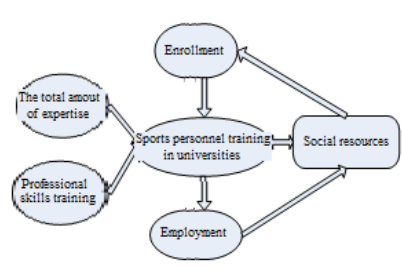

Figure1 The basic structure of the model

\subsection{The main problems of the simulating model}

The research models for Sports Professional Training Mode are mainly theoretical, so there are mainly three problems in the study:

First, the main source of sports professionals is university, and sports professionals cultivated by community only account for a small proportion ${ }^{[4]}$. During the association management, the difference between the amounts of Sport Talents cultivated by society and universities will affect the validity of the results or cause the shock of the model. Therefore, this article adds the adjustment process in the simulation, that is to say the accumulated value will be adjusted according to the estimates of the actual amount. The compared results of variable adjustment of cultivation of sports talent is in Figure 2:

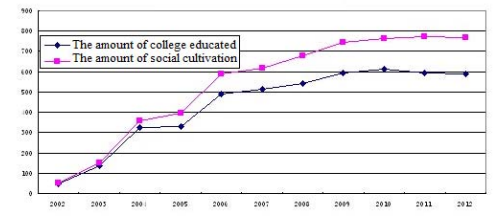

Figure 2 The compared results of variable adjustment of cultivation of sports talent

Second, sports is a new major in universities, therefore the data can be used is limited ${ }^{[5]}$. Take Sichuan for example, about 39,421 personnel with a professional sports professional in Sichuan that means the quantity of sports professionals are far from the needs of development ${ }^{[5]}$. The limited number of training samples and diverse employment of college graduates cause accumulated amount increasing which decreases the sensitivity of simulation model.

\section{THE SIMULATION MODEL OF TRAINING MODE FOR SOCIAL SPORTS}

3.1 The principles of dynamic system-based simulation

\section{model}

The dynamic system-based simulation model of training mode for social sports talents uses enrollment, personnel training and the employment of Sports Major as subsystem to build the training system. It is a method for system simulation combining behavioral decision of the college personnel training and internal mechanism of education. The model simulates the behavior and decision-making rules of universities and the labor market to form a network, and changes input stream of the system to identify the complex causal link among college enrollment, personnel training and graduate employment. The model identifies the characteristics and weak points of College Sports Training to deepen the reform of education and teaching management in colleges, and trains qualified sports professionals meeting the requirement of social and enterprises by combining with social development and characteristics of employment.

\subsection{The system of simulation model for training mode}

The proper system of simulation model is the crucial part in the establishment of system dynamitic-based simulation model for training mode of talents. According to the characteristics of the Professional Training Mode of social sports, the model system combining social capital and the job market contains six basic flows: student flow, capital flow, equipment flow, knowledge flow, material flow and information flow. The structure of the presented simulation model is shown in Figure 3

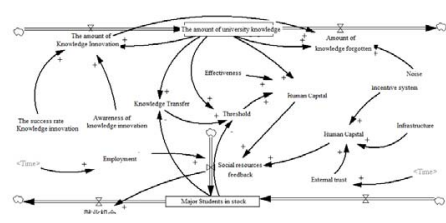

Figure 3 The structure of the presented simulation model

\subsection{The algorithm of the simulation model}

The ultimate goal of the establishment of system dynamics-based simulation model is to obtain the image of coordinates and two-dimensional icon of personnel training strategy and process of behavioral strategies through the simulation ${ }^{[6]}$. The basic DYNAMO equation of the model is designed according to the operating mechanism of the simulation model. The level equation of the simulation 
model (L equation) is as the following

$$
L_{1} \bullet K=L_{1} * J+D K *\left(R_{i} \bullet J K-R_{o} \bullet J K\right)(1)
$$

In formula (3.1), level variable $\mathrm{L}$ and rate variable $\mathrm{R}$ are the accumulated amount variables, DK and JK are auxiliary variables.

The rate equation ( $\mathrm{R}$ equation) of the simulation model is

$$
R_{1} \bullet K L=f\left(L_{1} \bullet K, A_{1} \bullet K, \ldots\right)
$$

In formula (3.2), level variable $\mathrm{L}$ and rate variable $\mathrm{R}$ are the accumulated amount variables, $\mathrm{K}$ and $\mathrm{A}$ are auxiliary variables.

The auxiliary equation (A equation) of the simulation model is :

$$
A_{1} \bullet K=g\left(L_{1} \bullet K, A_{2} \bullet K, R_{1} \bullet J K, \ldots\right)
$$

According to the actual situation of enrollment and employment, the initial value of $\mathrm{C}$ and $\mathrm{L}_{1}$ are set to 47 and 31.

The steps of the simulation model are as follows:

Step 1: enter the program and the original data.

Step 2: calculate the number of sports professional graduates in the next three years in accordance with the design value of the initial parameters.

Step 3: adjust coefficients of enrollment and the college social resources, and then observe changes in the number of sports professional students graduating in the next three years.

Step 4: adjust the coefficients of amount of knowledge sources and professional training, and then observe changes in the number of sports professional students graduating in the next three years.

Step 5: Determine the target value of the number of professional sports graduates in the next three years and adjust the coefficient of each amount, and then observe the changes.

Step 6: repeat the step 3 to step 5 until obtaining the best value of BRF, develop reasonable use of strategies of social resources and university personnel training.

\section{SIMULATION}

To test the validity and sensitivity of the simulation model, data of enrollment and employment, professional courses setting and talents training status of sports students in Sichuan Province from 2002 to 2012 are selected as objects to be analyzed in the research, and VENSIM software is used to forecast the results.

\subsection{The figure of simulation}

The experimental data is from the Universities of

\begin{tabular}{|c|c|c|c|c|c|c|}
\hline Variable/Time point & 0 & 2 & 4 & 6 & 8 & 10 \\
\hline Knowledge in source & 75 & 129.2 & 4163.2 & 3206.16 & 260.38 & $\begin{array}{l}328.8 \\
6\end{array}$ \\
\hline Knowledge in universitie & 25 & 19.48 & 20.04 & 20.63 & 21.22 & 21.84 \\
\hline $\begin{array}{c}\text { External human capital i } \\
\text { Universities }\end{array}$ & 0 & 10.00 & 29.07 & 55.44 & 105.73 & $\begin{array}{l}201.6 \\
2\end{array}$ \\
\hline $\begin{array}{c}\text { External human capital o } \\
\text { Universities }\end{array}$ & $\mathbf{f}_{0}$ & 0.05 & 0.14 & 0.41 & 1.18 & 3.43 \\
\hline $\begin{array}{c}\text { Structural capital of } \\
\text { Universities }\end{array}$ & 0 & 0.01 & 0.04 & 0.11 & 0.32 & 0.93 \\
\hline
\end{tabular}
Sichuan, and the validity of the results are shown in Table 1 .

TABLE 1 THE RESULTS OF VALIDATION

It can be inferred from Table 1 that the simulation model is validated. In the simulation model, changes in the total amount of knowledge in knowledge source and changes in the total amount of social resources are shown in Figure 4 and Figure 5:

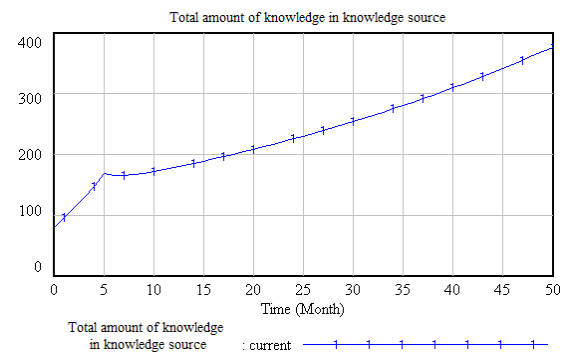

Figure 4 changes in the total amount of knowledge in knowledge source

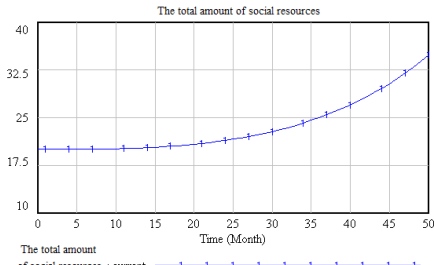

Figure 5 changes in the total amount of social resources

The trends of external human capital, internal human capital and universities structural capital of universities are shown respectively in Figure 6, Figure 7 and Figure 8. 

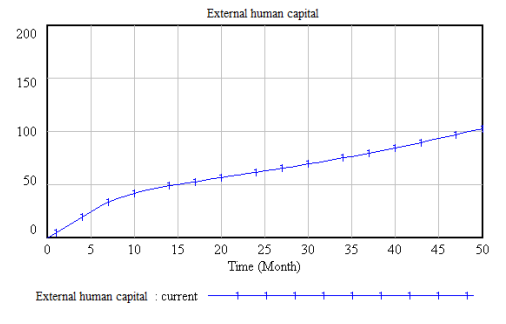

Figure 6 trend of external human capital
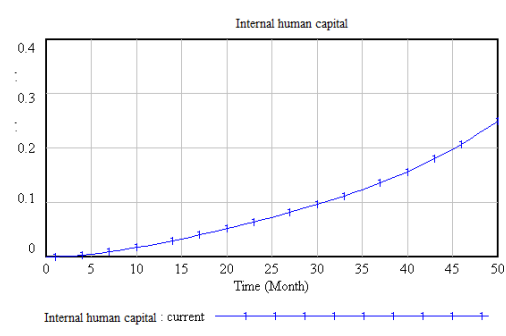

Figure 7 trend of internal human capital

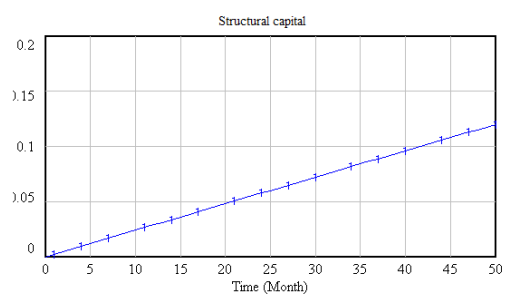

Structural capital : current

\subsection{Analysis of the results}

The comparison results of predicated value and actual value are shown in Figure 9.

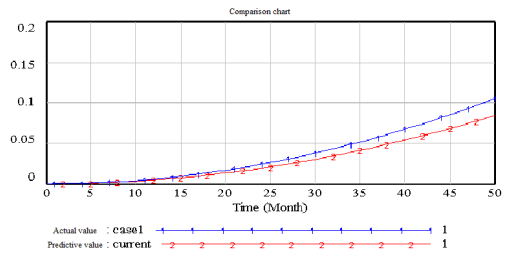

Figure 9 the comparison results of predicated value and actual value

It can be inferred from Table 1 and Figure 9 that although the simulation model is validated, the value predicated is a little less than the actual value. The results indicate that the model needs further improvement. Additionally, the amount of special talents has certain impacts on the simulating results even adjusting the amount of social special talents. In conclusion, the proposed model for training mode of sports talents based on system dynamics satisfactorily simulates the operation of the training mechanism, rapidly obtains relatively accurate results and has excellent convergence. Although the stability and accuracy need further study, the proposed dynamitic-based simulation model for training mode of talents has obvious reference value and using value.

\section{CONCLUSIONS}

On basis of the Data of Sichuan Province Sports Talents Cultivation in ten years, the paper builds a simulation model for personnel training mode and solves the problems of complex factors by system dynamics. The results show that the simulation has the advantages of high effectiveness, high accuracy and relatively easy operation. Therefore, it has a high reference value for mechanism reform of universities. Currently, lots of universities in China should establish reasonable system for professional courses, and train the talents meet the social requirements.

\section{REFERENCES}

[1] Mcclellan J H, Rader C M. Number Theory in Digital SignalProcessing. Englewood Cliffs, NJ: Prentice-Hall, 1979

[2] Krishna B, Krishna H C,. Lin K Y.Computational NumberTheory and Digital Signal Processing: Fast Algorithms and Error ControlTechniques. CRC Press, Boca Raton, FL, USA, 1994.

[3] Grossschadl J. The Chinese Remainder Theorem and its application in a high-speed RSA crypto chip. 16th Annual Conference on Computer Security Applications, ACSAC '00, 2000:384-393

[4] LV Suhong,REN Yanna. Design and Realization of Web for Facial Recognition[J]. Bulletin of Science and Technolog, 2012,9(28):186-188.

[5] Wang An,Jiao Meipeng,Zhang Xiaodong. Investigation of Spectrum Correction Algorithm for Detection of Domestic 18 kinds of Information Frequency-shift Signal[J]. Computer Simulation, 2012.2.11-12.

[6] Guruswami V, Sahai A, Sudan M. 'Soft-decision' decoding of Chinese remainder codes. in Proc. 41st IEEE Symp. Foundations Computer Science, Redondo Beach, CA, 2000:159-168 